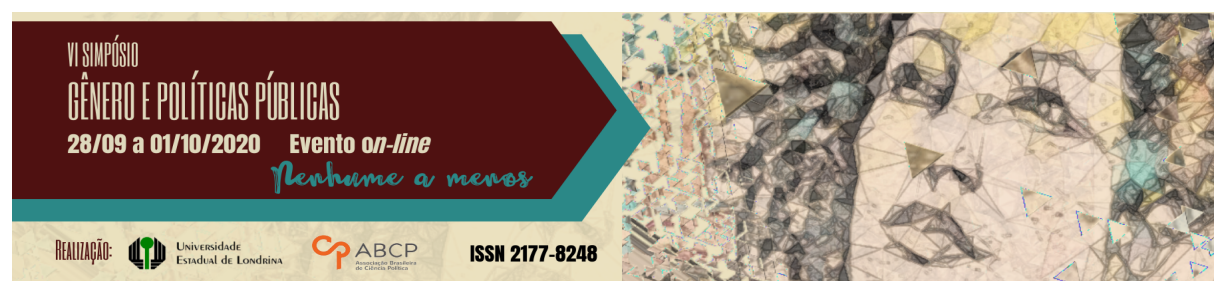

\title{
Não faz o requisito: vivências transgressoras no trabalho
}

\author{
Eduardo Milani Boselli ${ }^{1}$; Luís Paulo Nallin de Oliveira²
}

\section{Resumo}

As relações de gênero no ambiente empresarial são objetos de diversos estudos na Administração. Partindo da crítica de que as empresas não são espaços neutros em termos de gênero, determinados corpos são valorizados quando inteligíveis em sua apresentação heterossexual normativa e branca. Diante disso, nesta pesquisa buscamos compreender as vivências de pessoas transexuais nas empresas. Neste estudo, classificado como qualitativo descritivo, foram realizadas três entrevistas semiestruturadas com três pessoas transexuais em Londrina, PR. O estudo revelou que é problemático os modos como as relações de gênero são vivenciados nas organizações por pessoas transexuais, ficando evidente o enfrentamento de preconceitos e sofrimento no local de trabalho.

Palavras-chave: gênero; transexualidade; organizações.

\section{Does not make the requirement: transgressive experiences at work}

\begin{abstract}
Gender relations in the business environment are the subject of several studies in management. Based on the criticism that companies are not gender-neutral spaces, certain bodies are valued when they are intelligible in their normative and white heterosexual presentation. Therefore, in this research we seek to understand the experiences of transgender people in companies. In this study,
\end{abstract}

\footnotetext{
1 Mestrando pelo Programa de Pós-graduação em Administração da Universidade Estadual de Londrina (PPGA-UEL), eduwhoami@gmail.com.

2 Mestrando pelo Programa de Pós-graduação em Administração da Universidade Estadual de Londrina (PPGA-UEL), luispaulonallin@gmail.com.
}

GT 14 - Gênero, trabalho e sindicalismo 
classified as qualitative descriptive research, three semi-structured interviews were conducted with three transsexual people in Londrina, PR. The study revealed that the ways how gender relations are experienced in organizations by transgender people is problematic, and it is evident that prejudices and suffering in the workplace are confronted.

Keywords: gender; transsexuality; organizations.

\section{Introdução}

As organizações empresariais estão no papel central em relação ao sustento de muitas pessoas, seja direta ou indiretamente. Assim, o trabalho é uma importante fonte de renda, ao mesmo tempo que é atravessado por diferentes discursos, como a meritocracia, que delegam aos sujeitos a responsabilidade de seus futuros. Tal discurso aponta que para se ocupar uma vaga de trabalho basta a/o candidata/o atender aos requisitos da vaga, independente de seu gênero, raça ou classe social. Cria-se a imagem de que as empresas são locais neutros em que as vagas de trabalho estão disponíveis para todas/os.

Vivemos em um contexto socialmente estratificado, logo, não compreendemos tais organizações como locais neutros de gênero, nem como locais onde qualquer pessoa qualificada poderia assumir alguma função. Pelo contrário, trazemos aqui a concepção de organizações estruturadas de modo generificado (ACKER, 1990; FLORES-PEREIRA, 2010; HOPE, 2011; KERFOOT, 2000).

Adentrando esta ideia chegamos na limitação de gênero através de uma matriz binária emergente como construção social (BUTLER, 2003). Assim, as organizações são generificadas em estâncias específicas de gênero, sendo a heteronormatividade predominante na formação das organizações, institucionalizando a normalização dessa "regra" (KERFOOT, 2000).

Por outro lado, pessoas transgênero rompem com pressupostos da matriz binária estabelecida do "normal" (LANZ, 2014) e, consequentemente, possuem vivências dentro das empresas que são 
diferentes das experimentações binárias de gênero socialmente naturalizadas. Entretanto, existem dificuldades organizacionais que são relacionadas ao gênero, como a ascensão na hierarquia organizacional, postos de trabalho "invisíveis", discrepância salarial e tratamento inadequado quanto ao nome, são algumas situações enfrentadas (ACKER, 2011; AET, 2007).

Dessa forma, este trabalho tem como objetivo compreender as vivências de pessoas transexuais nas empresas. O texto está estruturado em três momentos principais: a relação do gênero e as organizações; a transexualidade e seus impasses no trabalho; e, por fim, as falas das/os participantes. $O$ trabalho justifica-se por auxiliar na emergência da discussão de vivências muitas vezes marginalizadas, principalmente no meio empresarial.

\section{Gênero e organizações}

As organizações empresariais frequentemente são vistas como espaços sem gênero em que existem apenas hierarquias e cargos para serem preenchidos. É justamente esse aspecto que é problematizado por importantes teóricas feministas (ACKER, 1990; FLORES-PEREIRA, 2010; HOPE, 2011; KERFOOT, 2000). Assim, as organizações não são espaços neutros em termos de gênero, mas locais de dominância de corpos masculinos heteronormativos.

Este debate não é novo, na década de 1990, Acker (1990) já havia abordado as organizações como generificadas, em contra ponto ao debate feminista da época que compreendia as organizações como neutras quanto a gênero. O gênero então não é inserido na organização por um meio ou força externa, mas é constituinte da estrutura organizacional como um elemento presente na formação das relações sociais (SCOTT, 1995).

Para além da constituição da estrutura organizacional, Butler (2003) traz que gênero é performativo, uma construção social, uma 
sequência de atos em que não existe um ator nem fazedor por trás do feito. Não há então, nenhuma relação necessária entre o corpo de alguém e o seu gênero. Para a filósofa "o gênero é performativo porque é resultante de um regime que regula as diferenças de gênero. Neste regime os gêneros se dividem e se hierarquizam de forma coercitiva" (BUTLER, 2002, p. 64).

Butler (2003) elucida que o modo como o próprio conceito de gênero produz uma identidade que passa a ser reconhecida como algo ontológico, algo pré-discursivo, anterior à relação e a discussão social. Assim, critica-se os conceitos que pressupõem supostas categorias universais, questionando, por exemplo, o conceito de "mulher", que frequentemente é tido como algo comum e compartilhado entre todas as mulheres. Nesse sentido, o termo "mulher", por exemplo, não esgota o que alguém é nem determina uma singularidade de opressão.

Ao deixarmos de pensar categorias universais relacionadas a identidade de sujeitos, poderemos então agir na estrutura jurídica (BUTLER, 2003), e criticar as categorias de identidades naturalizadas, uma vez que os sujeitos são formados discursivamente dentro de relações de poder sistematizadas. A desnaturalização dessas categorias universais é fundamental para pensarmos políticas e organizações mais equitativas.

Não é do ponto de organização "neutra" ou universal que partiremos, mas sim do ponto que as denuncia como estruturas de autoridade em que a heterossexualidade está institucionalizada (KERFOOT, 2000). Assim, Kerfoot (2000) argumenta a masculinidade como um discurso poderoso nas organizações, implicando diretamente em como os corpos se relacionam na estrutura organizacional.

Entendemos as empresas também como espaços em que são geridos os corpos das pessoas que ali trabalham. Nesse sentido, os signos que são apresentados nos corpos das pessoas no ambiente organizacional, conforme Kerfoot (2000), como a aparência física 
corporal, cor e gênero, se relacionam com características culturalmente aceitáveis, ou seja, a masculinidade hegemônica.

Tamanha é a força do discurso da masculinidade nas organizações que resulta na opressão dos corpos que não atendem aos requisitos culturais da categoria de gênero masculino. Em resposta a esse cenário, Kerfoot (2000) argumenta que são assumidos comportamentos e manifestações corporais associados à masculinidade hegemônica, como características competitivas, agressivas, instrumentais e "masculinas" na sua orientação.

Ao considerarmos um contexto social machista, a performatividade de gênero do "macho" adquire um aspecto ainda mais problemático nos ambientes organizacionais. Precisamente, Acker (2011) diz que, mesmo que as organizações não sejam as únicas responsáveis pela produção de desigualdade de gênero, elas fazem parte dos processos sociais do contexto mais amplo em que estão inseridas produzindo e reproduzindo discursos que corroboram com tais desigualdades.

Portanto, Acker (2011) traz as disparidades nas organizações como regimes de desigualdades, operando por meio das atividades que as constituem como organizações. A autora define desigualdade no contexto organizacional como:

As disparidades sistemáticas entre grupos de participantes organizacionais no controle de objetivos e resultados organizacionais, processos e decisões de trabalho, em oportunidades de entrar e avançar em determinadas áreas de trabalho, em segurança de função e níveis de remuneração, em prazeres intrínsecos do trabalho, e em respeito e proteção contra o assédio (ACKER, 2006, p. 110, tradução nossa).

Partindo da perspectiva interseccional, Acker (2011) traz que as relações de poder nas organizações estão ligadas a questões de gênero e raça, permeando (por meio de ideias relacionadas a quem é ou não adequada/o para trabalhos específicos) práticas como recrutamentos, 
contratação e promoções. A partir disso, tais práticas são geralmente burocratizadas e não visíveis por aquelas/es que são favorecidas/os pela existência de desigualdades.

\section{Transexualidade e trabalho}

Resgatando que o gênero é uma das relações primárias de poder (SCOTT, 1990) e pautados na identidade e diferença (entre os gêneros) acabamos por questionar o binarismo central nessas construções. Através da normalização de uma identidade privilegiada em um discurso tem sua diferença como limite, consequentemente, qualquer outra identidade passa a ser hierarquizada em posição inferior (SILVA, 2009).

O deslocamento de categorias socialmente naturalizadas que normaliza e normatiza, as pessoas transexuais desafiam os pressupostos dos constructos de homem e mulher, enfrentando diretamente a normalização do gênero e sua estrutura binária (KAFFER et al, 2016). Há também conflitos internos a respeito da própria conceituação da categoria transgênero, pois, apesar de romper com normas, pode-se reinserir na lógica binária ao performatizar uma categoria naturalizada (LANZ, 2014).

Consequentemente, uma pessoa transgênero não é apenas "alguém cuja identidade de gênero não corresponde à identidade sexual que lhe é atribuída à nascença" (THANEM, 2011, p. 193). Mas é, também, "uma circunstância sociopolítica de inadequação e/ou discordância e/ou desvio e/ou não-conformidade com o dispositivo binário de gênero, presente em todas as identidades gênero-divergente" (LANZ, 2014, p. 70).

A própria ideia de organização generificada de modo binário (ACKER, 1990) nos ajuda a compreender a profundidade do que significa esse processo de ruptura. Não há nas organizações de trabalhos formais a alocação de um gênero que foge à estrutura dual, 
evidenciando que as organizações não possuem espaços previamente definidos para pessoas transgêneros, tornando notável a incompatibilidade dessas existências com postos de trabalho formais.

A partir desse confronto entre a transgressão de gênero e o dispositivo binário de gênero, estudos científicos seguem em diversas direções. Tais focos retratam a solidão da mulher trans negra (PASSOS, 2016), exploram a potência epistemológica da teoria queer na resistência transviada (JUNIOR; DE LORENA SILVA, 2018) bem como a relação de pessoas transgênero com o trabalho (THANEM, 2011).

Ao considerarmos o contexto produtivo capitalista, o trabalho configura uma atividade com importância social. Aos voltarmos para as relações de trabalho, a Associação Espanhola de Transexualidade (AET, 2007) aponta as dificuldades mais comuns que pessoas transexuais enfrentam em relação ao trabalho formal, sendo:

1. Dificuldades no acesso ao mercado laboral [...] 2. Assédio no local de trabalho [...]. Negativa [...] em reconhecer a identidade de gênero da pessoa transexual durante o tratamento cotidiano [...]. Comentários paternalistas [...]. Comentários desrespeitosos por qualquer companheiro/a à condição transexual de qualquer caráter público [...]. Mobilidade funcional, adotada por uma motivação discriminatória: por exemplo, afastar uma pessoa transexual da atenção do público, mesmo que ela tenha desempenhado a função anteriormente, com a intenção de 'ocultar', tornando sua presença invisível. Discriminação salarial [...]. Restrição ou negação dos direitos laborais reconhecidos pela legislação ou pelo convênio coletivo aplicável, apenas pelo fato da condição de transexual [...]. Restrição dos direitos de proteção social que guardam a relação com o tratamento clínico da resignação do sexo [...]. 3. Medidas disciplinares, sanções e decisões de rompimento do contrato de trabalho (AET, 2007, p. 4-6, tradução nossa).

É importante também pensarmos a relação entre as vivências organizacionais de pessoas transexuais e suas trajetórias no sistema 
educacional. Tais instituições educacionais podem proporcionar arenas de disseminação do preconceito contribuindo com o aumento da evasão escolar. $\mathrm{O}$ abandono dos estudos tende a ocasionar baixa qualificação profissional, sendo este motivo uma das justificativas que empresas utilizam para não contratarem pessoas transexuais (KAFFER et al., 2016). Assim, há um efeito duplo de discriminação: o primeiro, ocorrendo principalmente na escola, está associado com o preconceito de gênero; já o segundo, associado com o "lugar ocupado (ou não ocupado) no mundo do trabalho" (DE SOUZA; BERNARDO, 2014, p. 163).

Maiores dificuldades, como o desrespeito ao nome social, foram encontradas em pessoas que estavam, por exemplo, no processo de transição. As pessoas neste processo contestam visivelmente a inteligibilidade da norma binária de gênero ficando mais expostas a dificuldades no trabalho. Neste ambiente, emergem diferentes preconceitos como, por exemplo, não respeitar o nome social relacionado a identidade de gênero da pessoa trans (KAFFER et al, 2016).

Não há aparato burocrático suficiente nem conhecimento para receber pessoas transgêneros nestas instituições. A burocracia em relação ao nome social emerge como mecanismos de discriminação, pois, a patologização da pessoa transgênero é condição suficiente para classificar como inapta para assumir postos de trabalho (KAFFER et al, 2016).

Em sua pesquisa, Cândido (2016, p. 2) elucida que todas as pessoas entrevistadas afirmaram sofrer algum tipo de preconceito, destacando os olhares, piadas, e palavras que desqualificam as pessoas. Seja por restrições de acesso, através da intolerância e resistência à mudança das próprias pessoas no trabalho. Por fim, preconceitos que acabam por conduzir a um isolamento social da pessoa, por medo e por rejeição (CÂNDIDO, 2016). 


\section{Perspectiva metodológica}

A pesquisa é caracterizada como qualitativa pois buscamos, por meio das falas das/os entrevistadas/os, compreender as relações de gênero vivenciadas por pessoas transexuais em empresas. Visto que $o$ foco da pesquisa são as pessoas e suas vivências em determinado contexto social, a abordagem qualitativa é essencial. Nesse sentido, Willig (2008) traz que o papel do pesquisador qualitativo requer um envolvimento ativo com os dados permitindo um elemento subjetivo no processo de pesquisa. A abordagem descritiva proporciona desvelar as relações existentes nos acontecimentos que foram relatados pelas/os entrevistadas/os, em consonância do que menciona Merriam (2009, p. 05, tradução nossa) de que "[...] o design qualitativo pretende sistematicamente descrever os fatos de um dado fenômeno [...]" sem almejar alcançar alguma origem ou causas iniciais nesse processo.

Para coleta de dados, foram realizadas entrevistas semiestruturadas com a participação de três pessoas. Tal instrumento possibilita a análise de aspectos particulares das/os participantes, bem como suas vivências (WILLIG, 2008). Como serão abordados temas íntimos, a conversa permite a fala livre das/os participantes e possibilita dados mais complexos. Nesse sentido, Merriam (2009, p. 90) esclarece que:

Neste tipo de entrevista, ou todas as perguntas são formuladas de forma mais flexível ou a entrevista é uma mistura de perguntas mais e menos estruturadas. Normalmente, deseja-se informação específica de todos os entrevistados, caso em que há uma seção mais estruturada para a entrevista. Mas a maior parte da entrevista é guiada por uma lista de perguntas ou questões a serem exploradas [...]. Este formato permite ao investigador responder à situação em questão, à cosmovisão emergente do inquirido e a novas ideias sobre o tema.

As/os participantes foram escolhidas/os pela identificação com os aspectos principais da pesquisa, ou seja, se identificam como 
transexuais e que estão ou já foram empregadas/os formalmente. A escolha das/os participantes foi realizada por meio da rede de contatos dos pesquisadores, e a partir disso se apoiou na rede de contatos das/dos entrevistadas/os que indicaram as/os demais participantes, atribuindo-lhes nomes fictícios.

Dois participantes, Zeon e Pedro, se identificaram na categoria "homem" e uma participante, Mariana, se identificou na categoria "mulher", sendo a/os participantes pessoas transexuais. Entendemos que as categorias "homem" e "mulher" estão relacionadas com diferentes vivências e em nenhum momento generalizamos as vivências das/os participantes. Para tratarmos das experiências nos locais de trabalho das/os participantes, é importante apontarmos nossa posição dentro da estrutura social estabelecida. Para Ribeiro (2017, p. 38):

quando falando de pontos de partida, não estamos falando de experiências de indivíduos necessariamente, mas das condições sociais que permitem ou não que esses grupos acessem lugares de cidadania. Seria, principalmente, um debate estrutural. Não se trataria de afirmar as experiências individuais, mas de entender como o lugar social que certos grupos ocupam restringem oportunidades.

Nos voltando ao local na estrutura social, este trabalho possui uma perspectiva queer e branca. Por fazermos parte da área da Administração, entendemos que, ainda que não seja o nosso lugar de fala, é necessário pensarmos criticamente organizações empresariais e suas relações com as pessoas. Por isso, conduzimos o trabalho com nossa arguição, sim, mas retratando histórias e, principalmente, vivências alheias. Colaborando com a ampliação da temática no espaço acadêmico brasileiro, sem, no entanto, objetivar ou nos apropriarmos das falas aqui inseridas.

Por fim, a respeito dos procedimentos de análises de dados. Estes foram realizados a partir do agrupamento das falas em torno de eixos de análise. Tais eixos, ou categorias, são descritos por Minayo (2001, p. 70) como o agrupamento de "elementos, ideias ou expressões 
em torno do conceito capaz de abranger tudo isso". Os eixos são denominados: 1. Requisitos para se trabalhar: construção de gênero nas organizações; 2. A vida no cotidiano: impasses no trabalho. Estes eixos foram definidos a partir da construção teórica, apresentada anteriormente.

Seguindo o princípio em que os dados devem ser alocados "a partir de um único critério de participação" (MINAYO, 2001, p. 72), os relatos associados com a performatividade de gênero, bem como a imposição sobre os corpos do gênero associados às funções organizacionais foram alocados no primeiro eixo. Os demais dados, seguindo o preceito de "exaustividade" mencionado por Minayo (2001), cujo todos os dados devem se enquadrar em uma das categorias, foram alocados sob os impasses e desigualdades nos locais trabalho. As categorias foram formuladas a fim de que os dados alocados em uma delas não sejam classificados na outra, seguindo o princípio de "as categorias sejam mutuamente exclusivas" (MINAYO, 2001, p. 72).

\section{Discussão e análise}

A discussão apresentada na sequência aborda as vivências de Mariana, mulher trans, e dos homens trans Pedro e Zeon, que relatam situações de empregos anteriores e atuais. Diferentes impasses emergiram a partir dos relatos, por um lado, existe a pressão para a manutenção das categorias de gênero culturalmente inteligíveis de "homem" e "mulher" no ambiente organizacional. Por outro, o preconceito também institui um modo de coerção social à inteligibilidade binária de gênero vigente atualmente.

Requisitos para se trabalhar: construção de gênero nas organizações

Gênero se mostrou como aspecto central nas relações no contexto empresarial, assim como abordado por Scott $(1990 ; 1995)$ ao trazer que gênero é um aspecto constituinte da estrutura organizacional, 
nesse sentido, ações performativas de gênero foram realizadas por Mariana, Pedro e Zeon. A expressão de um gênero culturalmente inteligível ("mulher" e "homem") se mostrou importante no local de trabalho. $\mathrm{O}$ ato performativo é parte constituinte da matriz binária de gênero, realizado por meio da repetição de ações que definem o sujeito como masculino ou feminino na lógica binária, assim, Butler (2000), salienta o fator produtivo da performatividade, pois, ao mesmo tempo que se institui em um presente, conforma um devir, um futuro e normatiza o que deve ser.

Destacamos o relato de Mariana, quando ela expressa essas ações presentes no início de sua transição por não se aceitar como pessoa trans tentando, segundo ela, "se adequar a uma cisnormatividade". No entanto, Mariana entende que essa atitude compreendia um apagamento de sua própria identidade. A entrevistada traz sua compreensão do que é ser mulher, Mariana diz que:

tentava chegar ao máximo me adequar ao que é esperado de uma mulher, mas enfim, hoje eu vejo que a mulher é um milhão de coisas e eu posso ser o que eu quiser, que inclusive ser uma mulher trans, que eu posso existir a minha maneira, independente de qualquer coisa.

Ainda que demonstre posicionamento político relacionado a gênero, Mariana destaca que no local de trabalho, que é propriedade de sua família, ela ainda não é tratada como mulher pelas pessoas que constituem a estrutura organizacional. Mariana foi registrada já com os documentos atualizados, apesar do registro, ela diz que “[...] a Mariana não trabalha lá". Para ela, isso se relaciona (não apenas) por não ser respeitada como mulher trans no ambiente de trabalho, mas também por atender ao seu "nome morto", denominação frequentemente utilizada para o nome no período pré-transição. A entrevistada menciona também que ainda não se posicionou explicitamente enquanto mulher trans no ambiente de trabalho por medo: "Eu vejo que, por mais que às vezes eu não queira admitir isso, mas eu vejo que é o medo mesmo, é um medo muito grande" (MARIANA). 
Ações performativas que caracterizam socialmente a categoria "homem" (que em si já é problemática, mas que aqui é citada em um feixe específico heteronormativo de homem), aparecem nas falas de Zeon como forma de se resguardar de possíveis preconceitos. Zeon relata que:

quando a patroa ia, o Roberto [gerente da loja] falava assim, 'Zeon, a Vilma [proprietária da loja] vem hoje'. Meu... meu, eu me encarnava um boy hétero, vocês não tão entendendo, era horrível. [...] eu precisava mostrar ali que eu era um homem ogrão, vamos dizer assim. (grifo nosso).

Pedro diz que no emprego atual há um bom relacionamento com seus patrões, mas decidiu não falar, por enquanto, sobre o seu gênero no trabalho:

Não que eu acho que é uma necessidade mas em certos momentos eu sinto uma pressão, eu mesmo me pressiono em contar. Eu sei que pra eles nada mudaria, continuaria tudo a mesma coisa, mas pelo fato de eu não ter a cirurgia da retirada de mama, tem certas roupas que você usa que aparece, que mostra alguma coisa ou outra, ou a nossa própria cabeça mesmo faz com que a gente pense isso, e por esse motivo eu achar que eles podem perceber ou que eles podem ver alguma coisa e eu não ter falado nada, eu sinto meio que uma pressão em contar. Mas não por conta deles, do trabalho em si, mas algo meu mesmo sabe?

Kerfoot (2000) diz que o discurso da masculinidade privilegia alguns corpos (masculinos) em relação a outros. Tal relação é percebida na fala de Zeon como uma adaptação das suas ações no intuito de não ter a sua sexualidade contestada. Mariana também relata uma vivência similar ao trazer que se enxerga performatizando ações que correspondem à uma ideia de masculinidade. Segundo ela:

eu me vejo performando uma identidade masculina pra poder corresponder as expectativas das pessoas. 
[...] o que acaba me segurando um pouco nessa empresa é a questão financeira.

A identidade de Pedro foi já foi contestada no trabalho anterior:

Dentro do próprio ambiente de trabalho eu tive que aguentar coisas do tipo você nunca vai ser um homem porque você não tem um órgão reprodutor e coisas do tipo.

Pedro então conta que ainda não fala sobre gênero no trabalho devido a essa experiência difícil, mas que não é algo que ele rejeite:

Eu acho que não tem nada que eu faça ou que eu fale que me distancie disso, né, deles ficarem sabendo. Eu só ajo normalmente [...] não me posiciono de uma forma tipo hétero cisnormativa, qualquer coisa do tipo. Mas o problema mesmo assim é o meu receio né, eu acho que é mais algo pessoal comigo mesmo do que com relação a outras pessoas, até porque eles são pessoas bem abertas então eu sei que não teria problema nenhum com isso. É o mesmo receio da outra empresa, se for ver, $[. .$.$] eu tinha medo de me$ mostrar, né, quem eu realmente era e já nessa eu não consigo contar o que eu já fui, no caso.

A apresentação de signos culturalmente relacionados a determinado gênero é algo que Kerfoot (2000) destaca como estratégia para acessar a ideia que se tem de masculinidade hegemônica. Nesse sentido, não é com prazer que Mariana e Zeon dizem agir de forma associada à uma masculinidade com a qual não se identificam, pesando o aspecto financeiro nessas circunstâncias.

A vida no cotidiano: impasses no trabalho

Zeon relata vivências de momentos durante sua transição até o seu posicionamento explícito enquanto homem trans. Em nenhuma das empresas nas quais Mariana e Zeon relataram suas vivências houve algum tipo de tratamento equitativo relacionado ao gênero, dificultando o dia-a-dia no ambiente de trabalho, expondo Mariana e Zeon à situações de discriminação, resultando em formas particulares de sobrevivência nesses ambientes. 
Mesmo com os procedimentos burocráticos da admissão de Mariana sendo com seu nome social, no cotidiano este fato continua sendo ignorado. Essa situação condiz com o que Keffer et al (2016) e AET (2007) trazem sobre o preconceito enfrentado no trabalho relacionado ao não respeito ao modo como as pessoas transexuais se identificam. Nesse sentido, Mariana fala sobre as dificuldades enfrentadas:

é muito exaustante você, você não ter sua identidade respeitada no trabalho, porque você fica sustentando uma pessoa que não faz sentido, que não tem mais nada a ver com você que você não se sente representada naquilo que você está fazendo. [...] eu não imaginava o quanto, o quão difícil seria [...] pra eu ficar mantendo essa identidade que não é minha, eu imaginava que seria mais fácil. Mas, ah, com o tempo eu, hoje, eu percebo que está sendo quase insuportável pra eu conseguir manter essa pessoa que, $[\ldots]$ não tem nada a ver comigo.

Pedro conta que também enfrentou preconceitos:

Trabalhei em uma empresa [...], até então quando eu entrei lá, não tinha feito a retificação de documentos. Então eu entrei lá com o nome antigo, com o nome feminino. Como não tinha retificado não tinha nada, eu tinha muito aquele negócio do medo, de expor, de falar pras pessoas, de pedir o respeito. Então eu acabava aceitando, né. Um erro um pouco da minha parte por isso.

A necessidade do trabalho para sobrevivência é um aspecto evidenciado nas falas de Mariana, Pedro e Zeon que se relacionam a estratégias como performar comportamentos culturalmente associados a um gênero. Zeon fala:

Não é por eu ser o terceiro gênero da nossa sociedade e ter uma orientação sexual totalmente diferente da deles que vai mudar isso [qualidade do empenho no trabalho], mas eu não vou mentir pra você, isso [sobre performar estereótipo] já, eu já me questionei muito, tipo assim, não é o que eu quero, só que eu 
preciso trabalhar. E daí a gente acaba enfrentando certas coisas que nos fazem mal pra poder sobreviver, né (grifo nosso).

A coerção opressiva do discurso da masculinidade ocorria na vivência da Mariana muitas vezes de forma velada, e, para Zeon, as piadas aparecem como essa repressão. Tais opressões, como no trabalho de Cândido (2016), os preconceitos aparecem como olhadas, piadas, e desqualificação das pessoas. Mariana relata:

eu consigo enxergar o preconceito nessas pessoas, mesmo sendo uma relação [...] que não existem muitos conflitos mas enfim, eu vejo que o preconceito tá sempre intrínseco ali [...] embaixo nos panos. Geralmente nunca me falaram nada, né. Mas eu percebo pelos olhares é... pelo modo que às vezes conversam comigo, o modo de falar comigo, é.. são coisas muito sutis mas que eu consigo notar assim [...], e que incomoda. [...] as pessoas [...] olham de uma forma agressiva.

Enquanto para Zeon:

rolava muita piadinha, né, muita brincadeira na época, né, dos próprios seguranças. Porque as vezes, sempre tinha alguém que confundia, confundia não, tipo assim, a pessoa olhava 'oi moço, que não sei que', a hora que eu virava 'ai me perdoa não sei o que' aí os caras me zoavam muito [...] Os caras faziam muitas brincadeiras chatas, [...] brincadeiras idiotas, tipo, as vezes quando eu ia levar uma pizza embora, é... o auxiliar do pizzaiolo ele ia escrever o nome na caixa, ele me zuava, sabe assim?

$\mathrm{O}$ desrespeito relacionado às piadas citadas por Zeon inibe a própria satisfação ou agrado em realizar o trabalho, gerando um processo recursivo de desigualdade no trabalho. $\mathrm{O}$ desrespeito no trabalho, apontado pela AET (2007), ocorre também de modo explícito em algumas situações contadas por Mariana, e, quando esses discursos aparecem há o silêncio dos demais trabalhadores que permite a propagação dessas práticas. Mariana diz: 
nessa situação da piada transfóbicas que eu ouvi foi uma [...], foi os dois, foi o cliente com um dos funcionários [...]. E mais é, na maioria das vezes essas piadas homofóbicas, que existe muito assim, é... geralmente nunca ninguém, eu vejo que nunca ninguém interrompe ali, sempre, mesmo que não fale nada homofóbico mas ele tá ali concordando tá dando risada, tá dando o aval ali de certa forma.

A falta de segurança na função e a perca do prazer no trabalho gerado pelas piadas e situações mencionadas estão interligadas com os regimes de desigualdade elucidados por Acker (2011). Tais regimes também são percebidos, como propõe a autora, por limitações a acessos de áreas de trabalho, em consonância, Mariana relata que anteriormente ao período de transição, costumava atender aos clientes no balcão, lidando diretamente com o público da loja.

Após o início do processo de transição, a entrevistada aponta que, conforme o citado pela AET (2007) da mobilidade do funcionário de modo discriminatório. Segundo Mariana, ela foi mudada de função na empresa para uma em que o contato com os clientes se dá de maneira mais distante, diminuindo seu contato e até a sua visibilidade em relação aos clientes. Mariana diz que:

Eu vejo que talvez essa minha transferência do balcão pro caixa talvez não foi só por uma necessidade, mas sim por eu imaginar que, a minha avó [...] talvez [...] esteja enxergando que a minha presença ali, que a presença da Mariana ali é uma coisa que incomoda. Então, eu acho que é um pouco dessa invisibilidade você não poder sair pra fazer uma cobrança porque eu não atendo aos padrões sabe? O outro funcionário que ela [...] falou pra ir fazer a cobrança é um homem branco, heterossexual que anda arrumado com camiseta, calça jeans, ou seja, ele atende mais talvez uma imagem mais corporativa, talvez. Por eu fugir completamente desse estereótipo, eu vejo [...] existe uma invisibilidade em que a minha existência incomoda, logo, 'não vamos deixar transparecer isso'. Por uma, talvez, uma imagem da empresa. 
Ao tratarmos os regimes de desigualdade em relação a dificuldade de acessos de trabalho, como apresentado pela AET (2007), Zeon diz que seus empregos foram conseguidos através de indicações e que por outras vias, vias convencionais utilizando currículos não surtiram nenhum efeito de contratação. Zeon relata:

$\mathrm{Na}$ verdade, até hoje, todos os empregos que eu trabalhei foram sempre por indicações. Eu só conseguia emprego por indicação. Gastava cem, duzentos reais, é.... imprimindo currículo, entregando pros lugares e nunca era contratado, né.

A sistematização dos regimes de desigualdade aqui se materializa no âmbito do trabalho de dois modos. O primeiro, relacionado com as dificuldades diárias ocorridas dentro das organizações devido ao gênero. Já na segunda, a própria negação da possibilidade de estar nesse ambiente, da própria possibilidade de existir dentro das organizações empresariais.

\section{Considerações finais}

É evidente a importância do trabalho, pois é a partir de sua renda que condições materiais mínimas de existência, como alimentação e moradia, são alcançadas. No entanto, é problemática a forma que as relações de gênero ocorrem nas organizações empresariais, marginalizando aquelas e aqueles que não correspondem aos requisitos de gênero culturalmente significados e aceitos. $O$ presente trabalho teve como propósito compreender as relações de gênero vivenciadas por pessoas transexuais nas empresas.

As empresas são frequentemente vistas como espaços neutros de gênero em que todas as pessoas podem ocupar, porém, foi discorrido que tal aspecto não condiz com as relações que acontecem empiricamente. Considerando que as organizações empresariais fazem parte do contexto social e acabam por reproduzir as suas desigualdades, é problemático pensarmos gênero nas empresas de forma não crítica, 
uma vez que o tecido social que fazemos parte possui regimes que investem em perpetuar práticas racistas, machistas, de fobias LGBTQI+, apenas para citar alguns exemplos.

$\mathrm{O}$ interesse em pessoas transexuais para a presente pesquisa se relacionou com a importância de que na área da Administração aconteça o debate sobre gênero e pessoas transexuais na dimensão do trabalho. Representa uma perda para a sociedade se considerarmos que a hegemonia dos debates em Administração seja relacionada a mecanismos de exploração, acumulação e dominação sob discursos de eficiência e produtividade.

Ficou evidente durante as análises dos dados o conceito de performatividade (BUTLER, 2003), principalmente quando as performances exercidas eram realizadas de modo a tentar amenizar os problemas enfrentados na rotina do trabalho. É possível observar que são vivências profissionais com desafios muito além daqueles que são comumente debatidos na área empresarial.

Vale dizer que apesar das desigualdades existentes nessas vivências, como visto, emergem-se pequenas estratégias para lidar e superar determinadas situações. Em vista disso, é importante, para próximos estudos, investigar quais e como se formam as diferentes estratégias de resistência no campo do trabalho, bem como os desdobramentos dessas resistências para novos modos de sociabilidade.

\section{Referências}

ACKER, Joan. Class Questions: Feminist Answers. Lanham, MD: Rowman \& Littlefield, 2006.

ACKER, Joan. Hierarchies, jobs, bodies: a theory of gendered organizations. Gender E Society, 1990.

ACKER, Joan. Theorizing gender, race and class in organizations. In: JEANES, Emma; KNIGHTS, David; MARTIN, Patricia (Ed.). Handbook of gender, work E organization. West Sussex: John Wiley \& Sons, 2011. 
AET, Associación Española de Transexuales. Cómo afrontar la transfobia en el puesto de trabajo. Espanha, 2007. Disponível em: http://transexualia.org/aspectos-legales/. Acesso em: 23 jan. 2020.

BUTLER, Judith. Criticamente subversiva. In: JIMÉNEZ, Rafael. Sexualidades transgresoras: Una antología de estudios queer. Barcelona: Icária editorial, 2002. p. 55-81.

BUTLER, Judith. Problemas de gênero: feminismo e subversão da identidade. Rio de Janeiro: Civilização Brasileira, 2003.

CÂNDIDO, Leandro Borges. Medo e preconceito: experiências de transgêneros no contexto organizacional. In: Congresso Brasileiro de Estudos Organizacionais, 2016. Anais [...]. 2016.

DE SOUZA, Heloisa Aparecida. BERNARDO, Marcia Hespanhol. Transexualidade: as consequências do preconceito escolar para a vida profissional. Bagoas-Estudos gays: gêneros e sexualidades, v. 8, n. 11, 2014.

FLORES-PEREIRA, Maria Tereza. Corpo, pessoa e organizações. Organizações \& Sociedade, Salvador, n. 54, p. 417-438, 2010.

HOPE, Angela. The body: a review and a theoretical perspective. In: JEANES, Emma; KNIGHTS, David; MARTIN, Patricia (Ed.). Handbook of gender, work \& organization. West Sussex: John Wiley \& Sons, 2011.

JUIOR, Dilton Ribeiro. DE LORENA SILVA, João Paulo. Corpos transviados ao Sul do Equador: o que Linn da Quebrada tem a nos (des) ensinar? Revista Cocar, v. 12, n. 23, p. 318-41, 2018.

KAFFER, Karen; RAMOS, Felipe; ALVES, Alvaro; TONON, Leonardo. A transexualidade e o mercado formal de trabalho: principais dificuldades para a inserção profissional. In: Congresso Brasileiro de Estudos Organizacionais, 2016. Anais [...]. 2016.

KERFOOT, Deborah. Body work: estrangement, disembodiment and the organizational "other". In: HASSARD, John; HOLLIDAY, Ruth; WILMOTT, Hugh (Ed.). Body and organization. London: Sage, 2000.

LANZ, Leticia. O corpo da roupa: A pessoa transgênero entre a transgressão e conformidade com as normas de gênero. 2014. Dissertação (Mestrado) - Universidade Federal do Paraná, Curitiba, 2014. 
MERRIAN, Sharan. Qualitative research: a guide to design and implementation. San Francisco: Jossey-Bass, 2009.

MINAYO, Maria Cecília de Souza (Org.). Pesquisa social: teoria, método e criatividade. Petrópolis: Vozes, 2001.

PASSOS, Maria Clara Araújo dos. Solidão da mulher trans negra. In: RODRIGUES, Carla; BORGES, Luciana; RAMOS, Tania Regina (Org). Problemas de gênero. Rio de Janeiro: Funarte, 2016. p. 49-52.

RIBEIRO, Djamila. O que é: lugar de fala? Belo Horizonte: Letramento, 2017.

SCOTT, Joan. Gênero: uma categoria útil de análise histórica. Educação \& Realidade, v. 20, n. 2, p. 71-99, 1995.

SILVA, Tomás Tadeu. A produção social da identidade e da diferença. In: SILVA, Tomás Tadeu. Identidade e diferença: a perspectiva dos estudos culturais. 3. ed. Petrópolis: Vozes, 2009.

THANEM, Torkid. Embodying transgender in studies of gender, work, and organization. In: JEANES, Emma; KNIGHTS, David; MARTIN, Patricia (Ed.). Handbook of gender, work \& organization. West Sussex: John Wiley \& Sons, 2011.

WILLIG, Carla. Introducing qualitative research in psychologie: adventures in theory and method. 2. ed. Berkshire: Open University Press, 2008. 